Review

\title{
Essential medicines management during emergencies in Pakistan
}

\author{
S.K.S. Bukhari, ${ }^{1}$ J.A.R.H. Qureshi, ${ }^{1}$ R. Jooma, ${ }^{2}$ K.M. Bile, ${ }^{1}$ G.N. Kazi, ${ }^{1}$ W.A. Zaibi ${ }^{1}$ and A. Zafar ${ }^{1}$
}

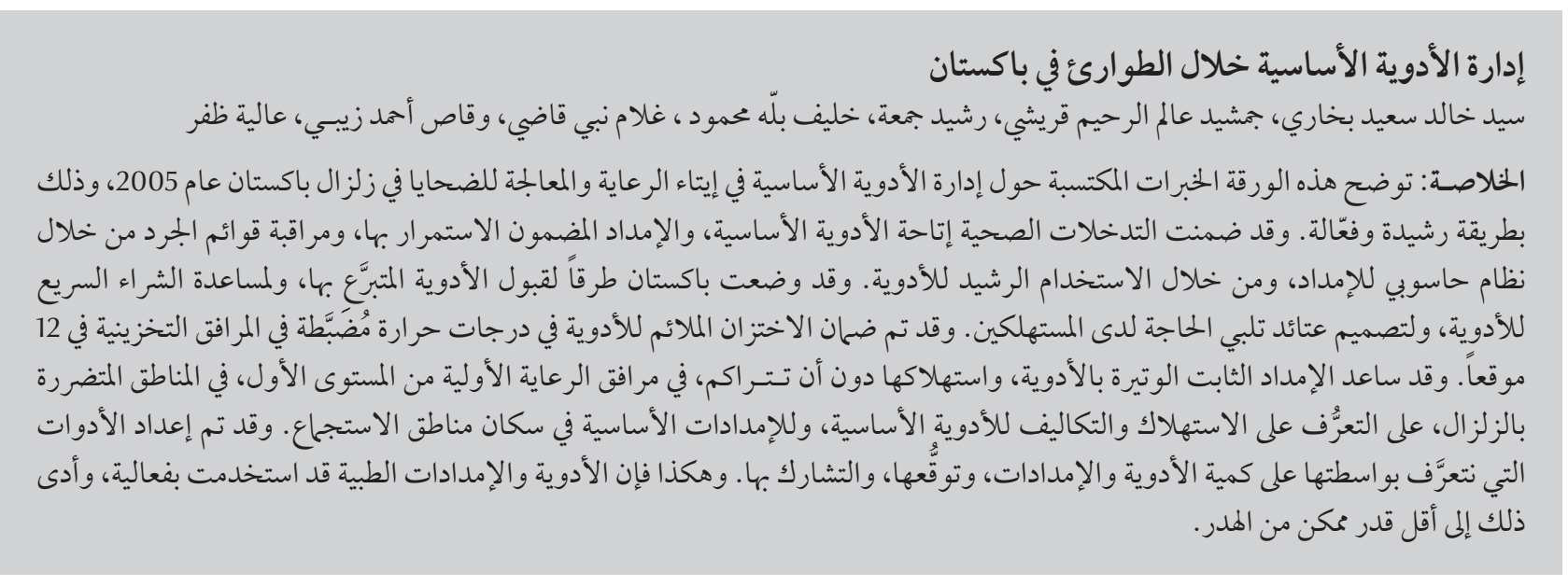

ABSTRACT This paper illustrates the experiences of essential medicine management in providing cure and care to victims of Pakistan's 2005 earthquake in a safe, rational and effective mode. The health interventions assured access to essential medicine, sustained supply, inventory control through a computerized logistic support system and rational use of medicines. World Health Organization Pakistan outlined modalities for acceptance of donated medicines, assisted in speedy procurement of medicines and designed customized kits. Proper storage of medicines at controlled temperature was ensured in warehousing facilities in 12 locations. A steady supply of medicines and their consumption without stock-outs in the 56 first-level care facilities of calamity-hit areas helped to ascertain the average consumption and cost of essential medicines and supplies for the catchment population. Tools for quantification and forecasting of medicines and supplies were developed and shared. Medicines and medical supplies were efficiently used resulting in minimum wastage.

\section{Gestion des médicaments essentiels pendant les situations d'urgence au Pakistan}

RÉSUMÉ Cet article décrit les processus de gestion des médicaments essentiels ayant permis de fournir un traitement et des soins aux victimes du tremblement de terre de 2005 au Pakistan, de manière sûre, rationnelle et efficace. Les interventions sanitaires ont assuré un accès aux médicaments essentiels, à un approvisionnement soutenu et à la gestion des stocks grâce à un système de soutien logistique informatisé et à une utilisation rationnelle des médicaments. L'Organisation mondiale de la Santé au Pakistan a expliqué les modalités d'acceptation des médicaments provenant de dons, a contribué à l'achat rapide de médicaments et a conçu des kits sur mesure. Un stockage approprié des médicaments à une température contrôlée a été réalisé dans des entrepôts situés sur douze sites. L'approvisionnement régulier en médicaments et une consommation sans rupture de stock dans les 56 centres de soins de premier niveau des régions touchées par la catastrophe ont permis de définir la consommation et le coût moyens des fournitures et des médicaments essentiels pour les populations desservies. Des outils de quantification et de prévision des médicaments et des fournitures ont été élaborés et diffusés. Les fournitures médicales et les médicaments ont été utilisés efficacement, ce qui a permis de minimiser le gaspillage. 


\section{Introduction}

Medicines at the right time to treat injured or sick people are vital elements in alleviating the anguish of people suffering during catastrophes [1]. Experience with problems and solutions concerning the use of pharmaceutical agents during disasters is very significant for disaster health care providers [2]. Better anticipation of needs on the basis of epidemiological data of experiences and improved field disaster assessment can provide enhanced medical care during disasters [2].

A comprehensive humanitarian operation followed the massive earthquake (7.6 on the Richter Scale), which devastated parts of northern Pakistan and Pakistan-administrated Kashmir in October 2005 affecting approximately 3.5 million people and taking a toll of about 73000 lives in an area of around $30000 \mathrm{~km}^{2}$ [3]. The response addressed the major challenges such as the harsh terrain hampering access, devastation of $68 \%$ of the health care infrastructure, and lifesaving relief efforts for the affected population residing in remote valleys. The special medical/surgical needs for 70000 severely injured patients were a priority matter [4].

Essential medicines that satisfy the priority health care needs of the population, in adequate amounts and appropriate dosage form with uninterrupted supply, are an integral component of primary health care [5]. During emergencies, their significance increases many times while rational use assumes critical proportions for primary health care delivery [6].

However, during emergencies, health service delivery infrastructure may fail to provide essential medicines to the affected population, who are often further poverty-stricken as a consequence of a calamity. Moreover, inadequate attention to the management of medicines can result in waste of valuable resources and deprive a suffering population from equitable access to this primary assistance. The management components of an essential medicine distribution system, which include warehousing facilities, supply chain system and inventorization, are interwoven, complex and crucial.

Evaluation reviews, for example from the Mexico 1985 earthquake or the Armenia 1988 earthquake, have repeatedly indicated that much of the medical supplies received from donor agencies as humanitarian assistance for the suffering population are not appropriate to their needs $[7,8]$. Rational arrangements for negotiating and receiving need-based medicines has entailed formulation of guidelines and standard operating procedures $[9,10]$. Receiving inappropriate medicine supplies can cause management problems and jeopardize an emergency operation; individuals with pharmaceutical training may facilitate the sorting of procured and donated pharmaceuticals [11]. Pre-screened need-based medicines customized in different types of kit to cater to the requirements of suffering population may be one of the best practices of essential medicine [10].

Widespread devastation caused by the earthquake in Pakistan necessitated significant improvements to the existing medicine management system. The pharmaceutical products and equipment arriving at disaster sites posed serious logistic and management challenges such as sorting tonnes of supplies while ensuring that urgently needed items reached the disaster victims on time.

The main objective of this paper is to document the experiences gained in the management of essential medicines during the severe and prolonged calamities in Pakistan, highlighting the best practices and lessons learnt in managing these essential medicines and supplies for the affected population.

\section{Methods}

The data were generated through a review of documents that included annual reports on essential medicine management during and after the earthquake, reports of consultative workshops, World Health Organization (WHO) guidelines, standard operating procedures and information collected from pharmacists located in the affected districts. In addition, the relevant literature was reviewed on the subject. The results were also validated from the data ascertained from the logistic support system software, which was customized and installed to suit the requirements of the warehousing, inventory control and supply chain of the essential medicines,

\section{Results}

WHO liaised with donors on essential medicine needs, developed protocols of pre-shipment approvals, and formulated and disseminated guidelines on a number of critical issues.

\section{Preparation and adaptation of guidelines/standard operating procedures}

Table 1 exhibits the list of 12 guidelines and standard operating procedures developed following global principles and disseminated by WHO during the course of the emergency, as well as their objectives and the outputs received. The management of essential medicines from receiving and warehousing to their distribution to health facilities was regulated by these guidelines and standard operating procedures.

\section{Prequalification of pharmaceutical products}

During the emergency, humanitarian agencies and donors commenced funding the humanitarium global Health Cluster through WHO for the provision of essential medicines. The 


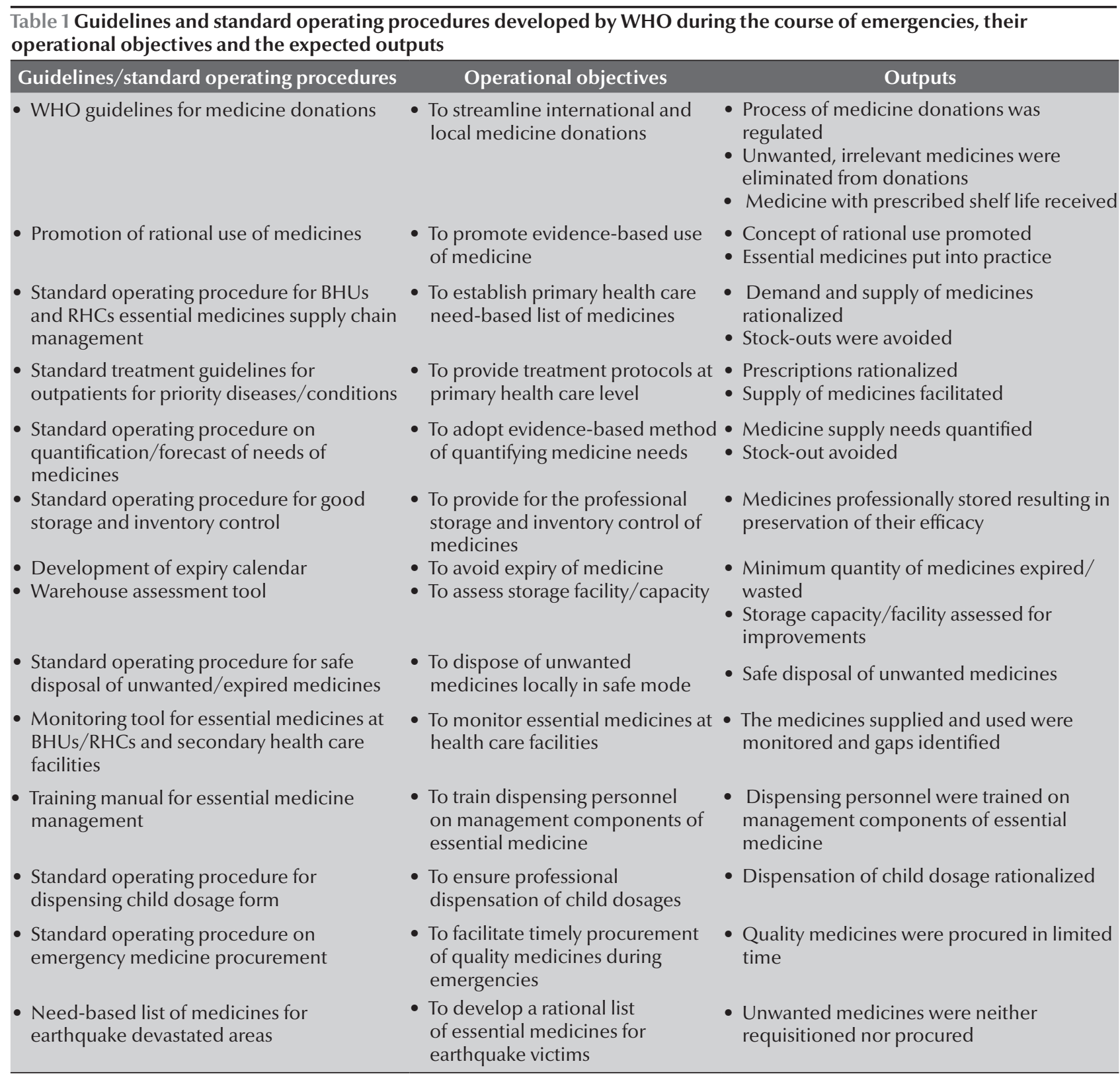

BHUs = basic health units; $R H U s=$ rural health units.

procurement of quality medicines in Pakistan had been a persistent concern of the donor agencies. The country has more than 500 medicine manufacturers and importers, having more than 50000 registered products, making procurement of cost-effective quality products complicated. To make the right selection, product-based prequalification criteria for local procurement were developed conforming to WHO guidelines: bioequivalence of generics in comparison with the innovator brands, biopharmaceutical classification and compliance with current good manufacturing practices adopted by the Drug Control Organization of the Ministry of Health, supported by its drug testing laboratories.

\section{Preparation of customized kits based on per capita essential medicines needs}

Table 2 illustrates flexibility and usefulness of the Mini Emergency Health Kit (MEHK) compared with the Interagency Emergency Health Kit (IEHK) listed therapeutic category and the dosage form along with their cost. In order to overcome size limitations, gaps and the cost of the available international kits, the medicine kits were customized to address the specific needs of the affected population during all phases of the emergency. The MEHK was modified from the IEHK to cater for primary health care needs including communicable, noncommunicable diseases and maternal neonatal and child health needs for a population of 6000 for one month. IEHK included 150 items: 51 medicines, 16 medical supplies and 83 assorted supplies. By 


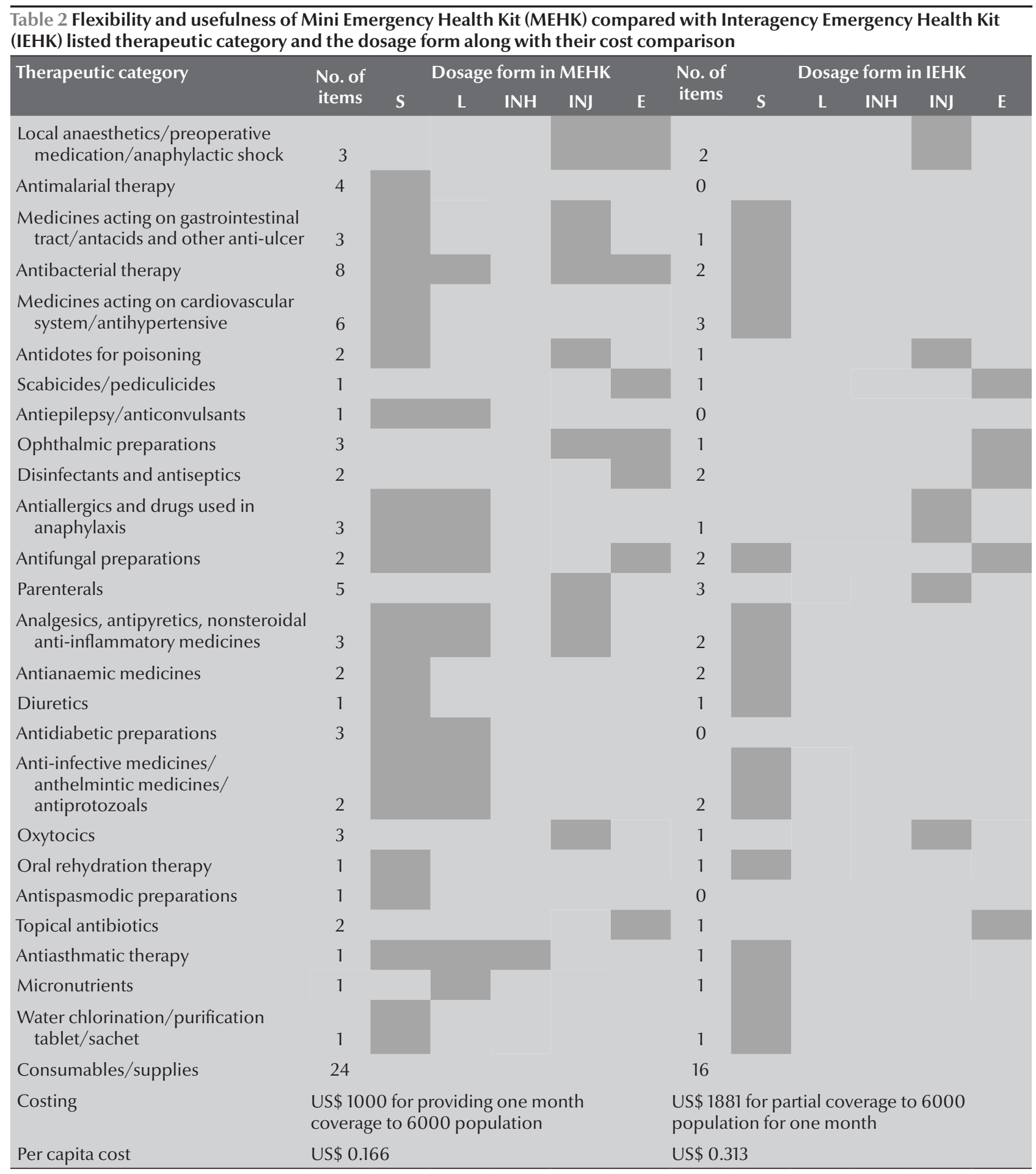

$S=$ solid preparations; $L=$ liquid preparations; $I N H=$ inhalation; $I N J=$ injectable; $E=$ external preparations. = dosage form available.

contrast, the MEHK consisted of 110 items: 86 medicines and 24 medical supplies catering for the treatment of malaria, diabetes, abdominal spasms, epilepsy and acute bronchial asthma. The medicines and supplies in the IEHK did not cover the diseases stated above or the dosage forms for all age groups and conditions. The per capita cost of an IEHK was estimated at US\$ 0.313 compared to US\$ 0.166 for a MEHK. The customized kits also included kits for personal protective equipment, antiscabies medicines and family hygiene, surgery, trauma, mental health, safe birth and cholera.

In the earthquake affected areas, 56 first-level healthcare facilities were regularly provided with the essential medicines without stock-outs till their use had stabilized. This intervention 
was regularly followed by monitoring to determine the consumption of essential medicines and supplies. Morbidity data and consumption data were used for forecasting and calculating the demands. In the subsequent year, consumption data of the previous year facilitated the estimation of per capita consumption and cost. These data also assisted to determine the composition of the MEHK.

\section{Wastage of medicines and supplies}

Figure 1 presents a comparison of wastage of medicines during major global disasters, where the authorities were confronted with operational challenges such as short shelf life, lack of expiry date and unsolicited donation: much medicine was wasted during major emergencies in recent decades compared to an average of $1.3 \%$ per annum waste in Pakistan varying from $0.8 \%$ to $2.1 \%$. This wastage was calculated from data ascertained from logistic support system records. In accordance with the set standard operating procedures all the expired/wasted medicines were recalled to a central warehouse and reentered into logistic support system. This revalidated the actual wastage and was disposed off according to $\mathrm{WHO}$ guidelines at high temperature incineration.

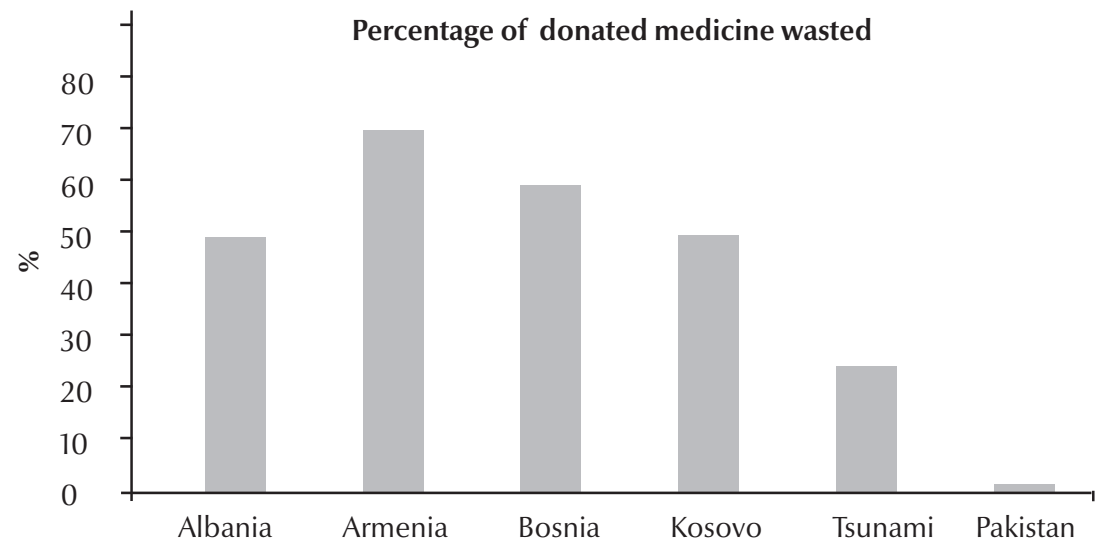

Figure 1 Comparison of wastage of medicines during major global disasters

\section{Coordination with medicine donors and major stakeholders}

Through collaboration of the Ministry of Health and $\mathrm{WHO}$, a donation receiving centre was established at the Pakistan Institute of Medical Sciences, the largest tertiary care hospital in the capital. Contacts were established with international donors informing them of the essential medicines, vaccines, biologicals and surgical supplies needed. Almost $25 \%$ of the medicines offered for donations were not accepted as they were either not relevant or possessed a short shelf life. WHO established sustainable partnerships with donors such as International Health Partners (UK), Health Partners International of Canada and AmeriCares (USA) to ensure donations conformed to WHO drug donation guidelines, rational selection and maximum shelf life. The core principles of these guidelines are: all donations should be based on an expressed need and that unsolicited drug donations are to be discouraged; donations should be supportive of existing government health policies; there should be no double standards: if the quality of an item is unacceptable in the donor country, it is also unacceptable as a donation; and there should be effective communication between the donor and the recipient. The Ministry of

between medical teams, partners and
donors.

\section{Supply chain management}

Table 4 depicts the magnitude of medicine donations received, medicines procured, the beneficiary population and wastage of medicines during 2005-09. The supply chain system was reinforced by establishing warehouses conforming to WHO standards such as good storage practices and inventory control. One central warehouse was established in Islamabad, two in Khyber-Pakhtunkhwa and nine in Balochistan for ongoing 


\begin{tabular}{|c|c|c|c|c|c|}
\hline $\begin{array}{l}\text { Scope of the essential medicine } \\
\text { management training }\end{array}$ & Location & No. of days & $\begin{array}{l}\text { No. of } \\
\text { trainings }\end{array}$ & $\begin{array}{l}\text { No. of people } \\
\text { trained }\end{array}$ & Sponsoring organization \\
\hline Concept of essential drugs & Islamabad & 3 & 1 & 8 TOT & WHO \\
\hline Good storage practices & KPK & 3 & 4 & 126 & WHO/UNICEF \\
\hline Prescription handling & AJK & 3 & 4 & 130 & WHO/UNICEF \\
\hline Good dispensing practices & KPK & 3 & 3 & 40 & WHO \\
\hline $\begin{array}{l}\text { Guidelines for dispensing child } \\
\text { dosage forms }\end{array}$ & AJK & 3 & 3 & 42 & WHO \\
\hline Proper handling of pharmaceuticals & Sindh & 3 & 3 & 86 TOT & WHO/UNICEF \\
\hline $\begin{array}{l}\text { Guidelines for detecting and } \\
\text { rectifying medication errors }\end{array}$ & Islamabad & 3 & 4 & 31 & WHO \\
\hline $\begin{array}{l}\text { Guidelines for disposing of } \\
\text { pharmaceutical waste }\end{array}$ & Balochistan & 3 & 1 & 8 & WHO \\
\hline Rational use of medicines & IDP camps & 1 & 18 & 192 & WHO \\
\hline $\begin{array}{l}\text { Handwashing } \\
\text { Logistic support system }\end{array}$ & & & & & \\
\hline
\end{tabular}

$W H O=$ World Health Organization; UNICEF = United Nations Children's Fund; TOT = Training of trainers; KPK =Khyber Pakhtunkhwa; AJK=Azad Jamu and Kashmir; $I D P=$ internally displaced persons .

operations and emergency preparedness. Pharmacists were engaged on a priority basis in order to assist the local government's health administration and WHO field offices to sort medical supplies and manage their inventory using the logistic support system. Pharmacists were assigned to monitor and evaluate the use of medicine, assist in avoiding stock-outs and promote rational use of medicine.

\section{Logistic support system}

Logistic and inventory software was installed and operated in the WHO central warehouse at Islamabad categorizing medicines by their generic name, dosage form, strength, batch number, expiry date, priority distribution and source. The system was advantageously used for generating reports of stocks distributed to suboffices, health facilities and mobile medical teams. Logistic and inventory software data also significantly facilitated WHO in the management audit of essential medicines.

\section{Capacity-building}

Table 3 shows the list of organized training activities on essential medicine management carried out during 200509 through WHO and United Nations Children's Fund (UNICEF) coordination. Training activities for health care providers were carried out on capacitybuilding in the management of essential medicines and on improving pharmacy practices in the public sector. Specific training modules were developed keeping in view local needs, gaps in capacity and areas for improvement.

\section{Discussion}

The drug management cycle, sustained with the appropriate support services, rational policy and legal framework, contributes significantly to maximize the output from the limited resources available for essential drugs, especially during emergencies $[12,13]$.

Preparation and dissemination of guidelines and standard operating procedures on principal aspects of medicine management proved to be rewarding for all stakeholders both at home and abroad $[10,12]$. As a result, donations of unwanted medicines were blocked, cost-effective procurement of quality medicines well managed and irrational medicine demands from health facilities and outreach teams carefully evaluated $[12,14]$. Good pharmaceutical practices for inventory control and storage regulated the supply chain system and preserved the medicines' efficacy [15]. The prime dividend of the tested standard operating procedures that were adapted for local conditions by following global principles was shown later on, during the crises in Khyber Pakhtunkhwa and the federally administered tribal areas, which have resulted in over 2.6 million internally displaced persons; the emergency medicines were managed without problem [12].

The WHO initiative of customizing kits for local conditions and specific diseases was beneficial to the health care providers, and the compact size of the kits made logistics easy [1]. Based on uninterrupted supply of essential medicines to front-line health facilities, an attempt was made to compute per capita consumption and cost of medicines. These kits were need-based, comprehensive and did not supply unwanted items. This innovative 


\begin{tabular}{|c|c|c|c|c|c|}
\hline Year & $\begin{array}{l}\text { Population catered } \\
\text { for (million) }\end{array}$ & $\begin{array}{c}\text { Donation of } \\
\text { medicines (US\$) }\end{array}$ & $\begin{array}{l}\text { Procurement of } \\
\text { medicines (US\$) }\end{array}$ & Wastage (US\$) & $\begin{array}{l}\text { Percentage } \\
\text { wastage }\end{array}$ \\
\hline 2005 & 11 & 4858326 & 1288159 & 79904 & 1.30 \\
\hline 2006 & 15 & 2728640 & 557446 & 69431 & 2.11 \\
\hline 2007 & 5 & 0 & 700416 & 5603 & 0.80 \\
\hline 2008 & 16 & 795180 & 806838 & 25632 & 1.60 \\
\hline 2009 & 47 & 4319603 & 2159074 & 61548 & 0.95 \\
\hline
\end{tabular}

experience of tailored kits suitable for the local conditions was cost-effective and convenient to primary health care providers $[2,10]$.

In the aftermath of the earthquake, the bulk of the medicines first received was stored efficiently $[15,16]$. Concurrent with the establishment of the central warehouse, $\mathrm{WHO}$ acquired the services of pharmacists for sorting and inventorying volumes of medicine stocks, making expiry calendars and promoting rational medicine use $[2,11]$. Installation of a logistic support system established transparency and traceability in the management of essential medicine and humanitarian supplies, facilitated audit of donated medicines along with a record of an individual Health Cluster partner's transactions. These schemes were instrumental in optimizing the use of procured and donated medicines during emergencies and resulted in a low level of medicine expiry.

Experience has demonstrated that donated medicines can create serious problems. In the earthquakes in Mexico City (1985) and Armenia (1988) the quantity of medicines and medical supplies received far exceeded the need and a significant percentage of the medicines had expired by the time it arrived at the disaster site $[7,8,17]$. A sizable portion was destroyed by frost, while the remainder that was relevant to the emergency was labelled without generic names [14]. In the Indian Ocean tsunami relief efforts in 2004, a substantial amount of donated medicines was reported to have been wasted [1]. The actual cost of disposing of unwanted medicines was significantly high [18]. A WHO audit of humanitarian medicine donations received in Albania during May 1999 for Kosovo refugees revealed that half of the medicines were inappropriate and required elimination [19]. Similarly in Bosnia, medicines were wasted due to either being inappropriate or lacking expiry dates [20].

On the contrary, operational guidelines, prescreening of medicines, placement of pharmacists, sorting and computerized inventorying, and good storage practices have significantly contributed to the limited waste of medicine in Pakistan which ranged between $0.8 \%$ and $2.1 \%$ during the past five years. The experience of essential medicine management during emergencies in Pakistan is marked by realistic planning, induction of operational guidelines and standard operating procedures, focused administration and continuous coordination of health cluster partners.

The medical and paramedical staff that were trained on essential medicines management in the districts affected by emergencies during the past few years were gainfully deployed by local governments for good storage and dispensing practices and proper handling of pharmaceuticals. This pool of human resources has been providing indispensable technical assistance in subsequent emergencies.

The essential medicines consultative workshop held eight months after the earthquake reflected the collective wisdom of stakeholders regarding lessons learnt, interventions that went very well and the things to bear in mind for future disasters. The factors that contributed to the successful operation in Pakistan included: effective liaison with international donors; preparation of a list of essential medicines according to the type and level of disaster; designation of focal persons for medicine management; induction of pharmaceutical expertise to implement inventory management software in disaster preparedness plans; preparation of a list of prequalified products; and continuing communication between health cluster partners for avoiding duplication and optimizing the use of existing medical supplies. The collective experiences shared and discussed through this consultative process was reliable and provided practice-based evidence for the future.

Preparation and dissemination of standard operating procedurestailored to local conditions are remarkably effective for coordination and optimal use of resources. Effective management techniques prevent stock-outs, while sound selection criteria enable filtering of quality products from a complex market. Medicine procurement and donations can be acquired and used most efficiently, provided the requisite standard operating procedures and trained human resources and management skills are in place from the start. 


\section{References}

1. Hechmann R, Bunde-Birouste A. Drug donations in emergencies: the Sri Lankan post tsunami experience. Journal of Humanitarian Assistance, 2007 (http://jha.ac/2007/09/26/ drug-donations-in-emergencies-the-sri-lankan-post-tsunamiexperience/, accessed 13 July 1020).

2. Hogan DE, Burstien JL. Disaster medicine. Philadelphia, Lippincott \& Williams, 2007.

3. Khadim MT et al. 8th October 2005 earthquake: an experience of diagnostic laboratory services in disaster. Pakistan Armed Forces Medical Journal, 2006, 56(4):433-437.

4. Pakistan 2005 earthquake: preliminary damage and needs assessment. Islamabad, Asian Development Bank, 2005.

5. Understanding essential medicines and primary health care Contact [Kenya] 2009, 187:2-3.

6. Van Damme WI, Van Lerberghe WL, Boelaert M. Primary health care vs. emergency medical assistance: a conceptual framework. Health Policy and Planning, 2002, 17(1):49-60.

7. Hairapetian A et al. Drug supply in the aftermath of the 1988 Armenian earthquake. Lancet, 1990, 335(8702):1388-1390.

8. Zeballos JL. Health aspects of the Mexico earthquake-19 September 1985. Disasters, 1986, 10:141-149.

9. Hogerzeil HV, Couper MR, Gray R. Education and debate: guidelines for drug donations. British Medical Journal, 1997, 314:737-740.

10. Forte GB. Private donations for former Yugoslavia. WHO Drug Information, 1994, 8(4).
11. Nestor A et al. Pharmaceutical services at a medical site after Hurricane Andrew. American Journal of Hospital Pharmacy, 1993, 50(9):1896-1898.

12. Management of drugs at health centre level: Training manual. Brazzaville, Regional Office for Africa, World Health Organization, 2004.

13. Pomatto V, Schuftan C. Review of quality assurance (QA) mechanisms for medicines and medical supplies in humanitarian aid: guidelines. Aachen, Germany, European Commission, 2006.

14. Guidelines for drug donation. Geneva, World Health Organization, 1999 (WHO/EDM/PAR/99.4).

15. Whybark $\mathrm{C}$. Issues in managing disaster relief inventories. International Journal of Production Economics, 2007, 108(1-2):228-235.

16. Autier $\mathrm{P}$ et al. HNP discussion paper: drug donations in postemergency situations. The International Bank for Reconstruction and Development, 2002.

17. Ciottone GR. Disaster medicine. St Louis, Mosby Inc., 2006.

18. Guidelines for safe disposal of unwanted pharmaceuticals in and after emergencies. Geneva, World Health Organization, 1999 (WHO/HTP/EDM/99.2).

19. WHO drug donation audit in Albania reveals many expired and unusable "gifts". World Health Organization, 1999 (http:// www.reliefweb.int/rw/rwb.nsf/db900SID/ACOS-64BF55?OpenDocument, accessed 13 July 2010).

20. Essential Drugs Monitor. Geneva, World Health Organization, 1999, (27). 